\title{
A Proposal to Classify Happiness as a Psychiatric Disorder
}

\author{
JOHN HARRIS, J. L. T. BIRLEY and K. W. M. FULFORD
}

\begin{abstract}
"It is proposed that happiness be classified as a psychiatric disorder and be included in future editions of the major diagnostic manuals under the new name: major affective disorder, pleasant type. In a review of the relevant literature it is shown that happiness is statistically abnormal, consists of a discrete cluster of symptoms, is associated with a range of cognitive abnormalities, and probably reflects the abnormal functioning of the central nervous system. One possible objection to this proposal remains - that happiness is not negatively valued. However, this objection is dismissed as scientificaly irrelevant."
\end{abstract}

The summary quoted above is from an article by Bentall (1992). The present authors were invited to comment upon the study.

\section{John Harris}

In his guide for the young academic politician, F. M. Cornford (1908) advises: "If you should write a book (you had better not), be sure that it is unreadable; otherwise you will be called 'brilliant' and forfeit all respect." Bentall's article is certainly very readable and is - I suppose self-consciously - 'brilliant'. It will doubtless be enjoyed and then dismissed by most psychiatrists, for this cleverness is deployed at the expense of their professional integrity. Such cavalier dismissal has, in a sense, been facilitated by Bentall himself, for he writes with a lightness of touch which makes it easier to think of his intention as principally humorous. However, despite some sloppy arguments or perhaps because of them, Bentall deserves to be taken seriously, not least because the sloppiness - and perhaps this is partly his point - is precisely mirrored in the psychiatric assumptions his paper challenges.

There will just be room here to note some examples of this 'sloppiness' and to indicate the ways in which defects in the quality of argument are clearly double-edged. In trying to make good the claim that if, in psychiatry, a disease is "a deviation from the norm which confers some form of biological disadvantage", then happiness is a disease in the sense in which Bentall makes this assertion.

"Consistent clinical evidence of an association between happiness, obesity and indulgence in alcoholic beverages has existed from before the time of scientific medicine (Julius Caesar, for example, is reputed to have asked for the company of fat men on these grounds). Given the well-established link between both alcohol and obesity and life-threatening illnesses it seems reasonable to assume that happiness poses a moderate risk to life. The common observation that happiness leads to impulsive behaviour is a further cause for concern."
Now many of the elements in this passage cry out for analysis, but the same devices are used in everyday psychiatric theory and practice in related ways. Take the use of the term 'clinical' for example; what work is it doing here? To talk of "consistent clinical evidence" implies something hard, rigorous, and scientific, and yet we are specifically told that such evidence is pre-scientific and indeed we are referred back to Julius Caesar via Shakespeare for the only example. ${ }^{1}$ Here, Bentall's use of the term 'clinical' is entirely consistent with the standard practice in medicine, where it is used to add spurious weight to dubious claims; as in the phrase "this is a matter of clinical judgement', of which, when uttered by a doctor, the literal translation is 'this is my business, not yours'.

Then there is the allegation of an association between happiness and obesity, obesity and indulgence in alcohol, and between all of these and lifethreatening illnesses. Well of course there is 'an association' between these things, but it is like the association between black skin and crime in New York City, or mother's milk and drug abuse. The corrupt slide here is between noting associated factors and alleging a causal connection. We must remember that these factors are supposed to 'confer' a biological disadvantage, and so happiness must plausibly 'confer' a life-threatening illness.

Then there is the tailpiece about happiness leading to impulsive behaviour - as if there were anything wrong or biologically disadvantageous about impulsive behaviour.

But of course all this is, or may be, part of Bentall's point. Namely that psychiatric theory is so poor that it relies on establishing equally spurious and tenuous connections between factors and on attaching sinister diagnostic meanings to innocuous traits like impulsiveness or forgetting bad past

1. Indeed, Shakespeare's Julius Caesar prefers fatness, not so much for its positive correlation with happiness or fatal illness, but for its supposed negative correlation with intelligence (Julius Caesar, Act I, Scene II). 
experiences. Bentall notes that "It has been shown that happy people ... are impaired when retrieving negative events from long term memory" - is this an 'impairment' of memory function? To suggest that it is seems to beg the question as to what is the proper function of memory? Perhaps the function of memory is to shield us from debilitating recollections? Astute readers will note here an equivocation over the meaning of the term, 'function'.

Bentall finishes in fine style, claiming that happy people are often irrationally biased in favour of themselves and have an unrealistic view of their own abilities, achievements, etc. "it is the unrealism of happy people that is more noteworthy, and surely clear evidence that such people should be regarded as psychiatrically disordered". Summing up, he concludes that:

"happiness meets all reasonable criteria for a psychiatric disorder. It is statistically abnormal, consists of a discrete cluster of symptoms, there is at least some evidence that it reflects abnormal functioning of the central nervous system, and it is associated with various cognitive abnormalities - in particular, a lack of contact with reality."

Again, it is clear that it is this lack of contact with reality which provides his surest ground. Yet when we come to look at the evidence adduced for "lack of contact with reality", we find that there is:

"consistent evidence that happy people overestimate their control over environmental events ... give unrealistically positive evaluations of their own achievements, believe that others share their unrealistic opinions about themselves, and show a general lack of evenhandedness when comparing themselves to others."

Again, there is equivocation over the meaning of the terms used. An unrealistic view is not necessarily any evidence at all for something that might properly be called "a lack of contact with reality", any more than a 'terrible play' - properly so called - is one that strikes terror into the hearts of its audience.

Indeed, even if it were, one of the leading contemporary philosophical psychologists has suggested that the reverse may be true and that lack of contact with reality might in fact be one of the hallmarks of sanity. Douglas Adams (1980) provides the illuminating parable of an inventor called Trin Tragula who:

"built the Total Perspective Vortex ... and into one end he plugged the whole of reality as extrapolated from a piece of fairy cake, and into the other end he plugged his wife: so that when he turned it on she saw in one instant the whole infinity of creation and herself in relation to it.

To Trin Tragula's horror, the shock completely annihilated her brain; but to his satisfaction he realised that he had proved conclusively that if life is going to exist in a universe of this size, then the one thing it cannot afford to have is a sense of proportion."
If Bentall has a strong point to make, it is that poor and tendentious argument, like that deployed in his paper, characterises the theory and practice of psychiatry. The extent to which this is true will be well enough known to readers of this journal.

Whenever I tease psychiatrists about their lack of a theory for mental illness or their inability to answer charges that mental illness is a myth, they always answer by showing me really distressed, unhappy people who need help which no other branch of medicine is offering. If this is a convincing answer, it is not so on the level of theory, and it is doubtful whether answering scepticism about the scientific respectability of psychiatry by showing rooms full of contented happy people will ever have quite the same force.

\section{J. L. T. Birley}

Richard Bentall's paper is a satirical squib. As befits a squib, he jumps about in no particular direction, exploding and briefly illuminating, while leaving large areas of darkness. Satire is in somewhat short supply in psychiatric education, so every contribution is welcome, particularly a witty one. All the best satire has a serious and well concealed purpose: this one presumably is in the field of its journal of publication, that is, medical ethics. The apparent thesis, the squib, need not be taken too seriously (Dr Bentall carefully avoids a discussion of the concept of a 'normal range'; whether of height, blood pressure, or mood). His serious ethical purpose is not stated, but I take it to be a concern with the dangers of 'overclassification' and 'over-medicalisation' of human behaviour, particularly by psychiatrists.

The various editions of the Diagnostic and Statistical Manual of the American Psychiatric Association (APA) can be seen as an example of this activity. In these, the word 'disease' has been removed and 'disorder' introduced instead. Does this make a difference? It may be an invitation to include fairly trivial conditions, so long as they can be empirically defined. The APA posits an "underlying biological disturbance" to be required before qualifying, but at the same time disclaims any sharp discontinuities between the 'normal' and the 'abnormal'. Furthermore, the APA claims that its approach is 'atheoretical'. Logically, this must be nonsense, as all observations are based on some underlying theory. In other words, the APA is in a muddle, compounded by poor databases for their separate disorders.

But all classifications are a muddle; they fit some parts of the observed population better than others, be it animal, vegetable, or mineral. At the same time, classification is a fundamental and essential human activity - an attempt to 'make sense' of the surroundings. 
This activity, as George Berkeley reminds us, is 'all in the mind'. 'Schizophrenia' exists only in doctor's minds, as an attempt to make sense of certain behaviour and experiences. The word itself is now rather antiquated, as are 'diabetes' and 'malaria'. Other sorts of words, as Dr Bentall will know, have been invented by psychologists for a similar purpose, and some are now looking a bit old-fashioned.

The ethical issues, presumably, are concerned with the powers which psychiatrists may have to control people, derived both from the law and from their professional authority, and with the possible and impossible extensions of these powers. (Fluoride in the water today, fluoxetine in the water tomorrow?)

However, a disease theory, based on presumed or identified brain pathology, should not be the only mental equipment of any psychiatrist. Such a dangerously limited person exists only, I hope, in the minds of others. To travel competently today, several more theories need to be added, including psychosocial, psychodynamic, developmental, disability, and neuropsychological. To improve our ethical guidance, we need to give close attention to issues of diagnosis, the types of tolerable and intolerable behaviour, and their appropriate treatment. The concepts, classification, and treatment of 'personality disorder' require particular scrutiny.

It may not be coincidental in this respect that Dr Bentall works not far from Ashworth Hospital, and that among those with the courage to protest about the regime there were some brave clinical psychologists.

\section{K. W. M. Fulford}

This is a spoof! Well, a reductio ad absurdum at any rate. Drawing on the criteria advocated severally by proponents of the disease model of mental disorder, Bentall suggests that happiness is a better candidate for that status than many well established disease categories, including his own pet hate, schizophrenia. The clear implication, then, is that since it is evidently absurd to classify happiness as a disease, it must also be absurd to classify schizophrenia as a disease.

The argument is well presented - it is witty, detailed, consistent. As a reductio, the point has been made before (Fulford, 1989), but the sharpness of Bentall's version of the argument consists in his choice of happiness as an 'absurd disease'. This, we feel compelled to agree, it really would be absurd to classify as a disease. But in coming to a conclusion, the absurdity of which is so self-evident, Bentall forces us to look critically not only at our own presuppositions but also at his. This is the danger with reductio arguments. They are the surgeon's scalpel of logical analysis, but the scalpel is double-edged.
It is worth looking briefly at an example of the use of a reductio argument in physics. The difficulties of psychiatric classification have sometimes been taken to be symptomatic of its deficiencies as a science. But physics is the paradigm science, so that any lessons drawn from it can be applied with some confidence to psychiatry. This example concerns no less a figure than Einstein. As is well known, although one of the founders of quantum mechanics, Einstein was deeply dissatisfied with it as a physical theory. He objected to its probabilistic nature, but his more serious concern was that it appeared, contrary to all scientific common sense, to involve instantaneous action at a distance. He put forward a number of arguments purporting to demonstrate this, most of which proved to be flawed. Eventually, though, together with two graduate students, Podolski and Rosen, he hit on a thought experiment which showed that either there was indeed instantaneous action at a distance (an evident absurdity) or else quantum mechanics was incomplete. So sharp was Einstein's argument here that it became known by an acronym - the EPR paradox (d'Espagnat, 1983). The end of the story is easy to guess. The EPR paradox was described in the 1930 s, but when the experiment was finally done in the 1970 s, the absurd happened. The quantum mechanical prediction, so evidently absurd, was fully vindicated (Aspect, 1986). This is not to say that quantum mechanics is complete, but any future theory which replaces it must now incorporate the instantaneous action at a distance to which Einstein - on grounds of its absurdity - so objected.

And if reductio arguments can cut two ways in physics, how much more so in psychiatry. Bentall's implied conclusion is that disorders like schizophrenia are not diseases because the criteria by which disease has been defined in the literature imply the absurd conclusion that happiness is a disease. It should be said straightaway that we are certainly not compelled to grant his conclusion. There are many points at which, aside from the spell of his prose, his actual case is weak: it is simply not true, for example, that happiness is connected unequivocally through obesity and alcoholism to an increased risk of premature death. His suggestion that happiness satisfies the "reduced life expectation" criterion of biological dysfunction advocated by Boorse (1975), Kendell (1975) and others, is thus highly questionable. He also neglects the other widely canvassed criterion, "reduced reproductive potential", altogether - and advisedly so, since by his own behavioural characterisation of happiness (as including a "high frequency of recreational interpersonal contacts"), we should expect the happy to be at a positive biological 
advantage! But even granting his conclusion, his implication (that schizophrenia is not a disease) fails to follow. For clearly, it could be the criteria of disease advanced in the literature which are at fault, not the status of schizophrenia. Moreover, as against the relatively hard-wired reductios of mathematical physics, this is not at all unlikely. For by these criteria, as a number of authors have pointed out (Caplan et al, 1981), many physical diseases, too, would not be diseases. On the balance of absurdities alone, then, Bentall's argument cuts differently from the way he intends.

There is a second lesson, though, from the EPR story - that no one, not even Einstein, has privileged access to the absurd. Our preconceptions are necessary to drive our research, but today's creative insight may be tomorrow's restrictive prejudice. There is something of this in Bentall's views on schizophrenia. These are hitched, if not to Szasz's star, at least to a star in the same constellation. The radical antipsychiatry of the 1960s was salutary in its day: it forced us to look more critically at the model of mental illness we had derived, largely unthinkingly, from physical medicine. But the debate has moved on. Within the conventional scientific tradition, there are more sophisticated models of schizophrenia than those to which Bentall refers (Roth \& Kroll, 1976; Wing, 1978). In the philosophy of medicine, there are well established analyses of the concept of illness which cut right through the difficulties about these models on which he relies (Nordenfelt, 1987; Fulford, 1989). These, it is true, require a certain amount of effort to assimilate; they are not the stuff of lightweight parody - no journalistic 'sound bites' here. But the way to avoid our preconceptions becoming mere prejudices is to expose them to the best that the opposition can throw.

This suggests a third lesson, for of course the EPR paradox was 'the best', so that in one sense the experimental vindication of quantum mechanics was a disaster. But in another sense it was a triumph, for the EPR results, precisely because they are by our current lights absurd, push physical theory forward most decisively. There is something of this, again, in Bentall's argument. It may not show the conclusion he intended, but it surely does point to the obscurity of the concepts we take for granted in our day-to-day practice. It is important to add - and this is a fourth lesson - that our concepts, including that of mental illness, are not thereby prejudiced.
In the EPR paradox, the self-evidence of the absurd conclusion hinged on the apparent transparency of such everyday concepts as object, location, and separation. However, the experimental vindication of quantum mechanics showed, not that these concepts are somehow 'invalid', but that a deeper understanding of them is required.

The distinction implied here, between the definition of concepts and their use, is often forgotten in the debate about mental illness. It is assumed - and this is surely a subtheme of Bentall's paper - that the valid use of a concept depends on the availability of a clear, explicit definition. The short answer to this is, try defining 'time'. The principal object of Bentall's argument, moreover, is not mental illness, but disease. To the extent that it is successful, therefore, and to the extent that it holds together as a reductio, it shows rather directly that the concept of disease itself is far more subtle than is generally recognised. There is some evidence that this may be important practically (Fulford et al, 1993). If it is, then Bentall, by provoking the reaction that he has, may inadvertently have achieved more for psychiatry in a few thousand words than other authors have achieved in a whole series of scholarly tomes. Such is the caprice of the reductio ad absurdum.

\section{References}

ADAMs, D. (1980) The Hitch Hiker's Guide to the Galaxy. London: Pan.

ASPECT, A. (1986) In The Ghost in the Atom (eds P. C. W. Davies \& J. R. Brown). Cambridge: Cambridge University Press.

Bentall, R. P. (1992) A proposal to classify happiness as a psychiatric disorder. Journal of Medical Ethics, 18, 94-98.

BOORSE, C. (1975) On the distinction between disease and illness. Philosophy and Public Affairs, 5, 49-68.

Caplan, A. L., Engelhardt, T. L. \& Mc Cartney, J. J. (eds) (1981) Concepts of Health and Disease: Interdisciplinary Perspective. Addison-Wesley.

CORNFord, F. M. (1908) Microcasmographia Academica. Cambridge: Bowes \& Bowes.

d'EsPackut, B. (1983) In Search of Reality. New York: Springer-Verlag. Fulford, K. W. M. (1989) Moral Theory and Medical Practice. Cambridge: Cambridge University Press.

- S SirRoff, A. Y. U. \& SNow, E. (1893) Concepts of disease and the abuse of psychiatry in the USSR. British Journal of Psychiatry (in press)

KenDELL, R. E. (1975) The concept of disease and its implications for psychiatry. British Journal of Psychiatry, 127, 305-315.

Nordenfelt, L. (1987) On the Nature of Health: An Action Theoretic Approach. Dordrecht: D. Reidel.

Rotr, M. \& KroLl, J. (1986) The Reality of Mental Illness. Cambridge: Cambridge University Press.

Wing, J. K. (1978) Reasoning about Madness. Oxford: Oxford University Press.

John Harris, Professor of Applied Philosophy, The Centre for Social Ethics and Policy, University of Manchester, Oxford Road, Manchester M13 9PL; J. L. T. Birley, Emeritus Psychiatrist, Maudsley Hospital, 133 Sydenham Hill, London SE26 6LW; K. W. M. Fulford, Research Psychiatrist, Department of Psychiatry, Warneford Hospital, Oxford OX3 7JX 